\title{
Cardiovascular Disease and Use of Renin-Angiotensin System Inhibitors in COVID-19
}

\author{
Chia Siang Kow ${ }^{1} \cdot$ Syed Tabish Razi Zaidi ${ }^{2}$ Syed Shahzad Hasan ${ }^{3}$ (i)
}

Published online: 13 April 2020

C) Springer Nature Switzerland AG 2020

\begin{abstract}
There is ongoing debate on the safety of renin-angiotensin system (RAS) inhibitors in COVID-19. Recently published studies highlight a potential relationship between cardiovascular disease (CVD) and COVID-19. This article aims to summarize the evidence on the use of RAS inhibitors in CVD patients with COVID-19, focusing on safety issues of the RAS inhibitors and their relationship with COVID-19.
\end{abstract}

\section{Key Points}

Cardiovascular disease (CVD) has been reported as one of the most common comorbidities among patients with severe COVID-19

The established benefits of ACE inhibitors and ARBs in CVD outweigh the uncertain risks among patients at risk of COVID-19

As of 4 April 2020, 1,139,207 confirmed cases of novel coronavirus disease 2019 (COVID-19) have been reported worldwide [1]. Examination of the full-length genome revealed that the coronavirus responsible for COVID-19, namely severe acute respiratory syndrome coronavirus 2 (SARS-CoV-2), is a $\beta$-coronavirus in the same subgenus as the severe acute respiratory syndrome (SARS) virus, but in a different clade [2]. The structure of the receptor-binding gene region is very similar to that of the SARS coronavirus in which both employ the angiotensin-converting enzyme 2 (ACE2) for cell entry [2]. ACE2, a negative regulator of

Syed Shahzad Hasan

s.hasan@hud.ac.uk

1 Faculty of Medicine and Health Sciences, International Medical University, Kuala Lumpur, Malaysia

2 School of Healthcare, University of Leeds, Leeds, UK

3 School of Applied Sciences, University of Huddersfield, Huddersfield, UK the renin-angiotensin system (RAS), is a homolog of ACE, where its expression can be identified principally in the heart, kidney, and airway epithelial cells [3]. It functions as a carboxypeptidase by converting angiotensin II to angiotensin-(1-7), thereby opposing the vasoconstrictive effect of angiotensin II [4].

Currently available epidemiological studies have reported an increased prevalence of cardiovascular disease (CVD), including hypertension, among patients who developed a severe subtype of COVID-19 [5-10]. For example, the study by Guan et al. [5], which is one of the earliest analyses of the characteristics of Chinese patients with COVID-19, reported that the prevalence of coronary heart disease was more than fourfold higher among patients who developed the combined primary endpoint of admission to an intensive care unit, mechanical ventilation, or death, relative to patients with less severe outcomes. In addition, more recent studies [9, 10] that evaluated COVID-19-associated cardiac injury observed a high prevalence of hypertension (59.8-63.5\%), coronary heart disease (29.3-32.7\%), cardiomyopathy (15.4\%) and chronic heart failure (14.6\%) among COVID-19 patients complicated with cardiac injury, which is independently associated with mortality with COVID-19.

Since then, researchers tend to favor an association of CVD with the severity of COVID-19 [11, 12]. Nevertheless, interpreting such an association should be done with caution, since the validity of such an association is hampered by an unclear definition of CVD, including hypertension, adopted in these studies [5-10]. Without knowing the baseline CVD status of patients, it is hard to suggest that CVD is an added risk factor for developing severe COVID-19 infection. Moreover, the available studies originated from China, 
therefore the generalizability of such an association to the global population is limited. Patients with underlying CVD are likely to experience excessive morbidity from any cause because they have diminished circulatory reserve to meet the excessive demands on the cardiovascular system. Furthermore, since the prevalence of CVD is increased with age, age may act as a confounding factor; available studies also reported that older patients with COVID-19 tend to develop a severe course of the disease, including the development of cardiac injury [5-10]. Future studies with age-stratified analysis could shed some light on the association of CVD with the severity of COVID-19 infection.

On the other hand, some researchers have called to consider the safety of RAS inhibitors, including ACE inhibitors and angiotensin II type I receptor blockers (ARBs), among patients with COVID-19 [11, 12]. There has been speculation that patients with COVID-19 who are receiving these agents may be at increased risk for adverse outcomes, given that ACE2 is a functional receptor for SARS-CoV-2 and RAS inhibitors can increase ACE2 levels [11, 12]. However, an increased level of ACE2 upon exposure to RAS inhibitors has not been a universal finding. While some animal studies [13-18] have noticed an increased expression of ACE2 upon exposure to ACE inhibitors or ARBs, other studies reported otherwise [19, 20]. The findings from human studies [21-24] have discredited the association of levels of ACE2 with the use of ACE inhibitors and ARBs, although one study [25] did notice an increased urinary secretion of ACE2 in hypertensive patients treated with the ARB olmesartan, but not with other ACE inhibitors and ARBs. Furthermore, another study [26] demonstrated an increased gene expression for ACE2 in the small intestine of patients under ACE inhibitor/ARB treatment compared with untreated controls. In addition, the elevation of serum ACE2 was only found in patients with unsatisfactory blood pressure control utilizing ACE inhibitor therapy, as reported in a study among hypertensive subjects [27]. Therefore, the effect of RAS inhibitors on ACE2 among human subjects is mainly due to the expression of ACE2 in the plasma, kidney and gastrointestinal system, and is not the known effect, if any, of RAS inhibitors on the expression of ACE2 in human airway epithelial cells. Furthermore, increased expression of ACE2 did not correspond to increased ACE2 activity in an animal study [16], and it is not known if the biological effect on ACE2 would wane immediately upon discontinuation of ACE inhibitors and ARBs.

The role of ACE2 in coronavirus infection is still controversial. Although ACE2 is a prerequisite for infectivity of SARS-CoV, the presence of other co-factors seems to be important for efficient cellular infection, since SARS-CoV was also identified in cell types lacking ACE2 expression [28]. In addition, the upregulation of ACE2 is not entirely harmful, since, paradoxically, an increased level of ACE2 might protect against coronavirus-induced lung injury [29]. Binding of the coronavirus spike protein to ACE2 leads to ACE2 downregulation, which in turn results in excessive production of angiotensin II [30]. As angiotensin II increases pulmonary vascular permeability, it could produce lung injury and impair lung function [30, 31]. Coincidentally, a study that investigated the clinical and biochemical parameters of patients with COVID-19 observed that levels of angiotensin II were higher compared with healthy controls [32]. Moreover, angiotensin II levels were linearly associated with lung injury, supporting the hypothesis that angiotensin II is responsible for lung injury in COVID-19. As previously mentioned, the clinical course of COVID-19 can be complicated by cardiac injury manifested by increased biomarkers, which portends a worse prognosis, and ACE2 plays a significant role in myocardial recovery response $[9,10,33]$. Indeed, in some of the heart samples from patients who died from SARS, the presence of viral RNA was identified, which was associated with reduced ACE2 protein expression [34].

The safety issue of ACE inhibitors and ARBs has since created great concerns on social media sites, but emerging data are reassuring. A retrospective observational study [35] published in the Chinese language reported that the use of ACE inhibitors or ARBs did not differ significantly between patients who recovered and patients who died from COVID-19, suggesting that the use of RAS inhibitors may not result in worse prognosis, although a conclusion on the safe use of RAS inhibitors could not be firmly drawn from this study due to the limited number of patients receiving RAS inhibitors $(n=22)$. However, another recent retrospective study [36] reported that COVID-19 patients with underlying hypertension taking ACE inhibitors/ARBs had a much lower proportion of critical disease $(9.3 \%$ vs. $22.9 \%$; $p=0.061)$ and a lower mortality rate $(4.7 \%$ vs. $13.3 \%$; $p=0.283)$ than their hypertensive counterparts not receiving an ACE inhibitor/ARB. Furthermore, patients taking ACE inhibitors/ARBs had significantly lower levels of C-reactive protein and procalcitonin when compared with patients not receiving an $\mathrm{ACE}$ inhibitor/ARB, suggesting a potential anti-inflammatory function in COVID- 19 .

RAS inhibitors could be indicated for chronic heart failure or chronic kidney disease, in which self-discontinuation of these agents without prior consultation with physicians may lead to decompensation within days to weeks, further compromising cardiopulmonary reserve in patients at risk of COVID-19 [37, 38]. The benefits that are specific to ACE inhibitors/ARBs may not be recapitulated by other antihypertensive agents for these diseases. While no data have been reported on the effect of temporary discontinuation of RAS inhibitors on mortality among patients with COVID-19, the shreds of evidence extrapolated from other patient settings suggest harm, in which studies from the Veterans Affairs Healthcare System showed that non-resumption of ARBs 


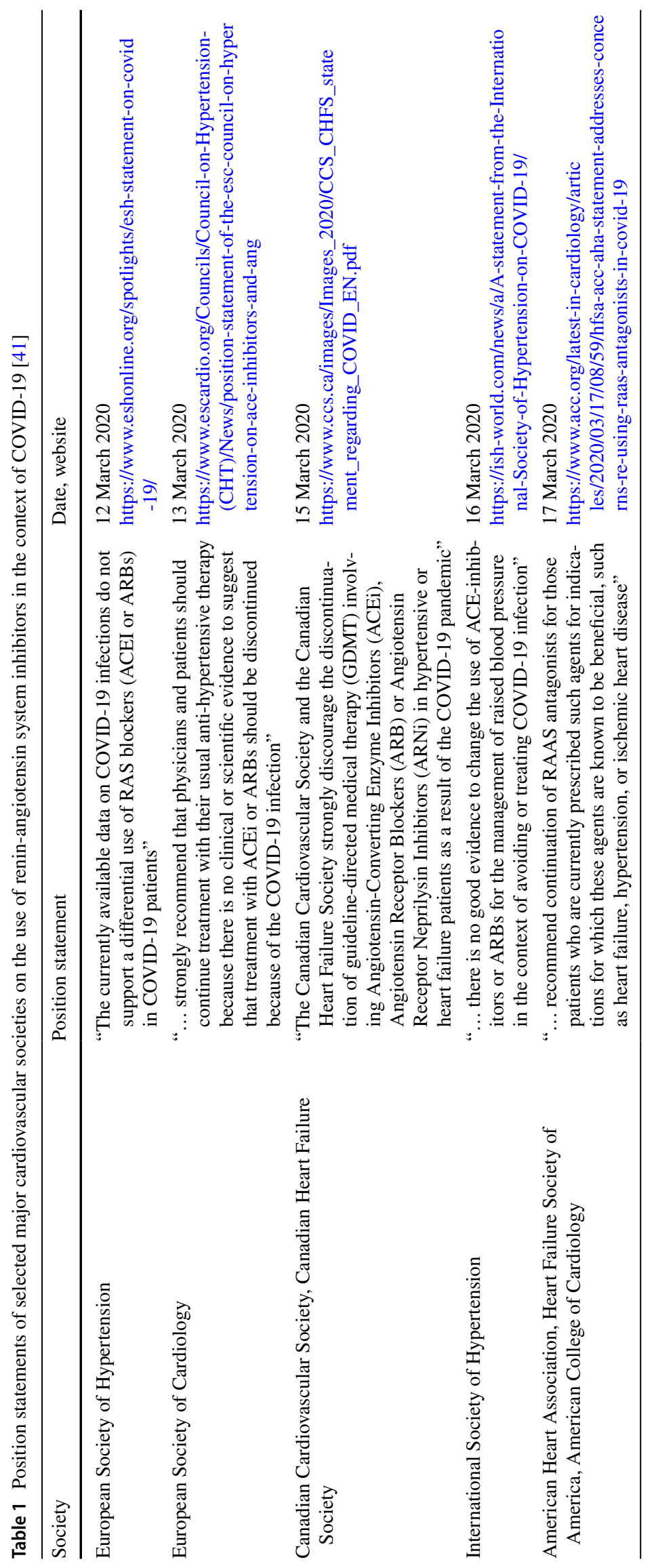


within 2 days, or ACE inhibitors within 14 days, after surgery was associated with higher 30-day mortality rates [39, 40]. The risk of fall in the elderly population from abruptly stopping long-term medication (e.g. ACE inhibitors) could result in significant adverse consequences by increasing the risk of fractures and bleeding.

In conclusion, although CVD has been reported as one of the most common comorbidities among patients with severe COVID-19, the association of CVD with the severity of COVID-19 has yet to be confirmed, since, thus far, there is no biological connection between CVD and viral replication. In addition, the established benefits of ACE inhibitors and ARBs in CVD outweigh the uncertain risks among patients at risk of COVID-19 since available evidence demonstrated no direct pathological relationship between RAS blockade and COVID-19. Therefore, we echo the position statements (Table 1) of some of the major cardiovascular societies [41] to discourage the discontinuation of ACE inhibitors or ARBs in patients with COVID-19. Such statements should provide reassurance to clinicians who would like to continue using ACE inhibitors and ARBs among patients at risk of COVID19. Furthermore, an ongoing clinical trial of COVID-19-infected patients receiving an ACE inhibitor/ARB randomized to either an alternative antihypertensive medication or continuation of the ACE inhibitor/ARB therapy may provide a definitive answer to this debate [42].

\section{Compliance with Ethical Standards}

Funding No external funding was used in the preparation of this manuscript.

Conflict of interest Chia Siang Kow, Syed Tabish Razi Zaidi, and Syed Shahzad Hasan declare that they have no potential conflicts of interest that might be relevant to this manuscript.

\section{References}

1. Dong E, Du H, Gardner L. An interactive web-based dashboard to track COVID-19 in real time. Lancet Infect Dis. https://doi. org/10.1016/S1473-3099(20)30120-1 (epub 19 Feb 2020)

2. Zhou P, Yang XL, Wang XG, et al. A pneumonia outbreak associated with a new coronavirus of probable bat origin. Nature. 2020;579(7798):270-3.

3. Hamming I, Timens W, Bulthuis ML, Lely AT, Navis G, van Goor $\mathrm{H}$. Tissue distribution of ACE2 protein, the functional receptor for SARS coronavirus. A first step in understanding SARS pathogenesis. J Pathol. 2004;203(2):631-637.

4. Vickers C, Hales P, Kaushik V, et al. Hydrolysis of biological peptides by human angiotensin-converting enzyme-related carboxypeptidase. J Biol Chem. 2002;277(17):14838-43.

5. Guan WJ, Ni ZY, Hu Y, et al. Clinical characteristics of coronavirus disease 2019 in China. N Engl J Med. https://doi.org/10.1056/ NEJMoa2002032 (epub 28 Feb 2020)
6. Zhang JJ, Dong X, Cao YY, et al. Clinical characteristics of 140 patients infected with SARS-CoV-2 in Wuhan, China. Allergy. https://doi.org/10.1111/all.14238 (epub 19 Feb 2020)

7. Zhou F, Yu T, Du R, et al. Clinical course and risk factors for mortality of adult inpatients with COVID-19 in Wuhan, China: a retrospective cohort study. Lancet. (published correction appears in Lancet, epub 12 Mar 2020) (epub 11 Mar 2020)

8. Wu C, Chen X, Cai Y, et al. Risk factors associated with acute respiratory distress syndrome and death in patients with coronavirus disease 2019 pneumonia in Wuhan, China. JAMA Intern Med. https://doi.org/10.1001/jamainternmed.2020.0994 (epub 13 Mar 2020)

9. Shi S, Qin M, Shen B, et al. Association of cardiac injury with mortality in hospitalized patients with COVID-19 in Wuhan, China. JAMA Cardiol. https://doi.org/10.1001/jamacardio .2020.0950 (epub 25 Mar 2020)

10. Guo T, Fan Y, Chen M, et al. Cardiovascular implications of fatal outcomes of patients with coronavirus disease 2019 (COVID-19). JAMA Cardiol. https://doi.org/10.1001/jamac ardio.2020.1017 (epub 27 Mar 2020)

11. Zheng YY, Ma YT, Zhang JY, Xie X. COVID-19 and the cardiovascular system. Nat Rev Cardiol. https://doi.org/10.1038/ s41569-020-0360-5 (epub 5 Mar 2020)

12. Fang L, Karakiulakis G, Roth M. Are patients with hypertension and diabetes mellitus at increased risk for COVID-19 infection? Lancet Respir Med. (epub 11 Mar 2020)

13. Ishiyama Y, Gallagher PE, Averill DB, Tallant EA, Brosnihan $\mathrm{KB}$, Ferrario CM. Upregulation of angiotensin-converting enzyme 2 after myocardial infarction by blockade of angiotensin II receptors. Hypertension. 2004;43(5):970-6.

14. Ocaranza MP, Godoy I, Jalil JE, et al. Enalapril attenuates downregulation of Angiotensin-converting enzyme 2 in the late phase of ventricular dysfunction in myocardial infarcted rat. Hypertension. 2006;48(4):572-8.

15. Soler MJ, Ye M, Wysocki J, William J, Lloveras J, Batlle D. Localization of ACE2 in the renal vasculature: amplification by angiotensin II type 1 receptor blockade using telmisartan. Am J Physiol Renal Physiol. 2009;296(2):F398-F405.

16. Ferrario CM, Jessup J, Chappell MC, et al. Effect of angiotensin-converting enzyme inhibition and angiotensin II receptor blockers on cardiac angiotensin-converting enzyme 2. Circulation. 2005;111(20):2605-10.

17. Zhong JC, Ye JY, Jin HY, et al. Telmisartan attenuates aortic hypertrophy in hypertensive rats by the modulation of ACE2 and profilin-1 expression. Regul Pept. 2011;166(1-3):90-7.

18. Klimas J, Olvedy M, Ochodnicka-Mackovicova K, et al. Perinatally administered losartan augments renal ACE2 expression but not cardiac or renal Mas receptor in spontaneously hypertensive rats. J Cell Mol Med. 2015;19(8):1965-74.

19. Burrell LM, Risvanis J, Kubota E, et al. Myocardial infarction increases ACE2 expression in rat and humans. Eur Heart J. 2005;26(4):369-24.

20. Burchill LJ, Velkoska E, Dean RG, Griggs K, Patel SK, Burrell LM. Combination renin-angiotensin system blockade and angiotensin-converting enzyme 2 in experimental myocardial infarction: implications for future therapeutic directions. Clin Sci (Lond). 2012;123(11):649-58.

21. Walters TE, Kalman JM, Patel SK, Mearns M, Velkoska E, Burrell LM. Angiotensin converting enzyme 2 activity and human atrial fibrillation: increased plasma angiotensin converting enzyme 2 activity is associated with atrial fibrillation and more advanced left atrial structural remodelling. Europace. 2017;19(8):1280-7.

22. Ramchand J, Patel SK, Srivastava PM, Farouque O, Burrell LM. Elevated plasma angiotensin converting enzyme 2 activity 
is an independent predictor of major adverse cardiac events in patients with obstructive coronary artery disease. PLoS ONE. 2018;13(6):e0198144.

23. Epelman S, Shrestha K, Troughton RW, et al. Soluble angiotensin-converting enzyme 2 in human heart failure: relation with myocardial function and clinical outcomes. J Card Fail. 2009;15(7):565-71.

24. Ramchand J, Patel SK, Kearney LG, et al. Plasma ACE2 activity predicts mortality in aortic stenosis and is associated with severe myocardial fibrosis. JACC Cardiovasc Imaging. 2020;13(3):655-64.

25. Furuhashi M, Moniwa N, Mita T, et al. Urinary angiotensin-converting enzyme 2 in hypertensive patients may be increased by olmesartan, an angiotensin II receptor blocker. Am J Hypertens. 2015;28(1):15-211.

26. Vuille-dit-Bille RN, Camargo SM, Emmenegger L, et al. Human intestine luminal ACE2 and amino acid transporter expression increased by ACE-inhibitors. Amino Acids. 2015;47(4):693-705.

27. Hristova M, Stanilova S, Miteva L. Serum concentration of reninangiotensin system components in association with ACE I/D polymorphism among hypertensive subjects in response to ACE inhibitor therapy. Clin Exp Hypertens. 2019;41(7):662-9.

28. Gu J, Korteweg C. Pathology and pathogenesis of severe acute respiratory syndrome. Am J Pathol. 2007;170(4):1136-47.

29. Kuba K, Imai Y, Rao S, et al. A crucial role of angiotensin converting enzyme 2 (ACE2) in SARS coronavirus-induced lung injury. Nat Med. 2005;11(8):875-9.

30. Imai $\mathrm{Y}$, Kuba $\mathrm{K}$, Rao $\mathrm{S}$, et al. Angiotensin-converting enzyme 2 protects from severe acute lung failure. Nature. 2005;436(7047):112-6.

31. Zhang H, Baker A. Recombinant human ACE2: acing out angiotensin II in ARDS therapy. Crit Care. 2017;21(1):305.

32. Liu Y, Yang Y, Zhang C, et al. Clinical and biochemical indexes from 2019-nCoV infected patients linked to viral loads and lung injury. Sci China Life Sci. 2020;63(3):364-74.

33. Kassiri Z, Zhong J, Guo D, et al. Loss of angiotensin-converting enzyme 2 accelerates maladaptive left ventricular remodeling in response to myocardial infarction. Circ Heart Fail. 2009;2(5):446-55.
34. Oudit GY, Kassiri Z, Jiang C, et al. SARS-coronavirus modulation of myocardial ACE2 expression and inflammation in patients with SARS. Eur J Clin Invest. 2009;39(7):618-25.

35. Peng YD, Meng K, Guan HQ, et al. Clinical features and outcome of 112 cases of novel coronavirus pneumonia in cardiovascular patients (in Chinese). Chin J Cardiol. 2020;48.

36. Yang G, Tan Z, Zhou L, et al. Angiotensin II receptor blockers and angiotensin-converting enzyme inhibitors usage is associated with improved inflammatory status and clinical outcomes in COVID-19 patients with hypertension. medRxiv 2020. https:// doi.org/10.1101/2020.03.31.20038935

37. Gilstrap LG, Fonarow GC, Desai AS, et al. Initiation, continuation, or withdrawal of angiotensin-converting enzyme inhibitors/ angiotensin receptor blockers and outcomes in patients hospitalized with heart failure with reduced ejection fraction. J Am Heart Assoc. 2017;6(2):e004675.

38. Pflugfelder PW, Baird MG, Tonkon MJ, DiBianco R, Pitt B. Clinical consequences of angiotensin-converting enzyme inhibitor withdrawal in chronic heart failure: a double-blind, placebocontrolled study of quinapril. The Quinapril Heart Failure Trial Investigators. J Am Coll Cardiol. 1993;22(6):1557-1563.

39. Lee SM, Takemoto S, Wallace AW. Association between withholding angiotensin receptor blockers in the early postoperative period and 30-day mortality: a cohort study of the Veterans Affairs Healthcare System. Anesthesiology. 2015;123(2):288-306.

40. Mudumbai SC, Takemoto S, Cason BA, Au S, Upadhyay A, Wallace AW. Thirty-day mortality risk associated with the postoperative nonresumption of angiotensin-converting enzyme inhibitors: a retrospective study of the Veterans Affairs Healthcare System. J Hosp Med. 2014;9(5):289-96.

41. Sparks MA, Hiremath $\mathrm{S}$, et al. The Coronavirus Conundrum: ACE2 and hypertension edition. NephJC. https://www.nephj c.com/news/covidace2. Accessed 5 Apr 2020.

42. Coronavirus ACEi/ARB Investigation (CORONACION). ClinicalTrials.gov identifier NCT04330300. Bethesda (MD): National Library of Medicine (US); 1 Apr 2020. https://clinicaltrials.gov/ ct2/show/NCT04330300. Accessed 5 Apr 2020. 